\title{
Social marketing-based communications to integrate and support the HEALTHY study intervention
}

\author{
LL DeBar $^{1}$, M Schneider ${ }^{2}$, EG Ford ${ }^{3}$, AE Hernandez ${ }^{4}$, B Showell ${ }^{5}$, KL Drews ${ }^{6}$, EL Moe ${ }^{7}$, B \\ Gillis $^{8}$, AN Jessup ${ }^{9}$, DD Stadler ${ }^{7}, M_{\text {White }}{ }^{10}$, and the HEALTHY Study Group \\ ${ }^{1}$ Center for Health Research, Kaiser Permanente Northwest, Portland, OR, USA \\ ${ }^{2}$ Department of Planning, Policy and Design, University of California at Irvine, Irvine, CA, USA \\ ${ }^{3}$ Center for Obesity Research \& Education, Temple University, Philadelphia, PA, USA \\ ${ }^{4}$ College of Education, Texas A\&M University, Corpus Christi, TX, USA \\ ${ }^{5}$ Planit Advertising Inc., Baltimore, MD, USA \\ ${ }^{6}$ Biostatistics Center, George Washington University, Rockville, MD, USA \\ ${ }^{7}$ Division of Health Promotion and Sports Medicine, Oregon Health \& Science University, Portland, \\ OR, USA \\ ${ }^{8}$ Western Psychiatric Institute and Center, University of Pittsburgh Medical Center, Pittsburgh, PA, \\ USA \\ ${ }^{9}$ School of Nursing, University of North Carolina at Chapel Hill, Chapel Hill, NC, USA \\ ${ }^{10}$ USDA/ARS Children's Nutrition Research Center, Baylor College of Medicine, Houston, TX, USA
}

\section{Abstract}

The HEALTHY study was a randomized, controlled, multicenter, middle school-based, multifaceted intervention designed to reduce risk factors for the development of type 2 diabetes. The study randomized 42 middle schools to intervention or control, and followed students from the sixth to the eighth grades. Participants were a racially, ethnically and geographically diverse cohort from across the United States. Here, we describe the conceptual underpinnings and design of the social marketingbased communications component of the HEALTHY study intervention that combined changes in the school nutrition and physical education (PE) environment with behavior change initiatives. The communications intervention component coordinated multiple elements to deliver campaigns that served to integrate and support all aspects of the HEALTHY intervention. The campaigns unfolded across five semesters of middle school, each targeting a specific theme related to the HEALTHY objectives. Communications campaigns comprised (1) core elements such as branding, posters, banners and visual and verbal messaging, (2) student events supporting the nutrition, PE and behavior intervention components through the application of social marketing and communications strategies, including the incorporation of student-generated media and (3) distribution of premiums and theme enhancers to extend the visibility of the study beyond the intervention environment. Formative

$£ 2009$ Macmillan Publishers Limited All rights reserved

Correspondence: Dr LL DeBar, Center for Health Research, Kaiser Permanente Northwest, 3800 North Interstate Avenue, Portland, OR, 97227, USA. E-mail: lynn.debar@kpchr.org.

Conflict of interest

The authors declare no conflict of interest.

An online Appendix shows an example poster using student generated media.

Supplementary Information accompanies the paper on International Journal of Obesity website (http://www.nature.com/ijo) 
research conducted with students, parents and school administrators was used to refine the communications strategy. Student peer communicators selected from the student body were involved to influence the normative student environment. Marketing and creative design experts developed a brand, logo, activities and materials. In the latter half of the study, student-generated messages and media were used to reflect local interests and culture and enhance peer influence. The HEALTHY intervention delivery and impact were strengthened by the communications strategies. The HEALTHY experience provides practical considerations for systematically incorporating a social marketing-based communications approach within future school-based health behavior interventions.

\section{Keywords}

type 2 diabetes; adolescents; social marketing; communications; school-based intervention; prevention

\section{Introduction}

HEALTHY was a 3-year randomized controlled study of a school-based intervention designed to reduce risk factors for type 2 diabetes. Seven centers in five states each recruited six middle schools serving largely minority and socioeconomically challenged populations. Schools were randomized to control or intervention arms of the study. ${ }^{1}$ In intervention schools, HEALTHY implemented an extensive multifaceted program including enhanced physical education (PE) classes, ${ }^{2}$ modification of the total school food service environment ${ }^{3}$ and a behavioral program designed to supplement the environmental changes and motivate students to improve their food choices and increase their physical activity. ${ }^{4}$ HEALTHY provided a unique opportunity to combine selected mass media outreach tools with more personalized forms of communication among a defined population over a multi-year effort with the aim of integrating and extending the impact of the three facets of the intervention.

The following describes the elements of the HEALTHY communications intervention component, with recommendations for incorporating social marketing-based promotional and education strategies in schoolwide lifestyle change interventions.

\section{Background and rationale}

Research on school-based interventions to decrease obesity suggests that environmental manipulation and/or health education alone may have limited impact. ${ }^{5}$ Appropriately targeted communication efforts may enhance outcomes by portraying the requisite healthy behaviors in a manner that taps into the values and priorities of the target audience. ${ }^{6}$ Social marketingbased strategies for health communications are increasingly being used to facilitate and support health behavior change. We define social marketing as 'the application of commercial marketing technologies to the analysis, planning, execution and evaluation of programs designed to influence the voluntary behavior of target audiences to improve their personal welfare and that of their society'. ${ }^{7}$ Social marketing methods borrow heavily from traditional marketing approaches, yet differ in their emphasis on intangible products, such as ideas, attitudes and healthy lifestyle changes. ${ }^{8}$ Social marketing aims to find ways to make the targeted health behavior more interesting, desirable, likable and beneficial to the target audience while minimizing perceived personal and social costs. ${ }^{9}$

Public health efforts to portray healthy lifestyles as attractive for youth may be particularly important in light of the reported $\$ 10$ billion per year spent in marketing high-calorie lownutrient food. ${ }^{10}$ In contrast to the influential advertising of commercial food manufacturers, 
the presentation of healthier options is often perceived as preachy, boring and arduous. ${ }^{11}$ Many social marketing efforts focus on mass media campaigns, specifically targeting large populations in given geographic areas using television, print ads and other media to deliver health behavior-related messages (for example, the recent VERB campaign promoting increased physical activity among 'tweens' 12,13 ). However, these methods are often not coordinated with local environmental and behavioral interventions, and as stand-alone campaigns have had few immediate or sustained effects. ${ }^{8}$ Social marketing efforts might be most effective in influencing behavior change when combined with other local and relevant strategies. ${ }^{14,15}$

\section{Intervention component elements}

The HEALTHY communications intervention component was designed to build excitement in the school to motivate and engage students to be more receptive to behavior, nutrition and physical activity changes introduced by the intervention and therefore to be more likely to internalize healthier behaviors. These communications efforts were delivered as unified campaigns to promote and support the HEALTHY targeted behaviors. ${ }^{1}$ Five specific campaigns were developed to address and unify the intervention themes for each of the five semesters. Each campaign was designed to present consistent, sequenced and repetitive messages/instructions for positive behavior change.

Several principal campaign elements were central to the communications approach, including branding, core elements (for example, posters), messaging, the use of student peer communicators (SPCs), sponsored events, and premiums and incentives. Each was developed and implemented with input from students, school personnel and study staff with expertise and responsibility for the three intervention components (nutrition, physical activity and behavioral change). Table 1 describes the components of these campaigns.

\section{Branding}

The process of brand development began with formative research. Multiple concepts were developed for campaign names, logos and messaging, and evaluated by focus groups consisting of students, parents and school staff from the various centers. The aim was to develop a brand identity that conveyed the essential character of the study in a memorable and appealing name and graphic representation (logo). Students suggested using a single direct 'strong' word that would resonate with all students regardless of their current eating or activity habits. After evaluating several different logos and campaign themes, the name HEALTHY set in a bold, innovative type font using the colors red, black and white was selected to uniquely identify the study. When coupled with the communications campaign, the brand identity provided a look and feel that helped to unify and integrate all study activities. To maximize impact and effectiveness, the HEALTHY brand and logo were used on all study materials, including workbooks, clothing and food labeling.

\section{Core elements}

Hallway posters, exterior and interior banners, messages in the PE class and cafeteria settings, and public address (PA) announcements delivered by SPCs addressing each semester's theme constituted the core communication elements (see Table 1). They were initially developed by experts in marketing and creative design to reflect the intervention strategies of the study in a way that would appeal to middle school students in their social (school) milieu. Posters and fliers were displayed at key locations around the schools, sometimes singly and sometimes in a cluster or tiled display to enhance visibility and impact. To encourage and support student participation during the later portions of the intervention, the study initiated a campaign to develop student-generated media. Posters and fliers were designed to incorporate student input 
in the form of pictures and phrases. Local school administrators approved design and message content in advance of production and dissemination. Initially, only study staff and teachers had shirts bearing the HEALTHY brand. Students liked the HEALTHY t-shirts so much that the study decided to provide branded t-shirts with different designs for all students in the study grade each year of the intervention. The branded t-shirts became interior markers or 'walking' advertisements for the study and reminders of the study message, and thus were considered a core element.

\section{Messaging}

Communication messages were designed to educate students about the study themes, promote study activities, encourage participation and highlight the study-related environmental changes being made in the schools. Message content generally originated with study staff and was then taken by experts in marketing and creative design to develop an appropriate format and media (or delivery options) to appeal to the targeted adolescent audience. For all messages, the principal intent was to produce content and dissemination options acceptable to the local communities and likely to resonate with the intended middle school students, that is, likely to spark conversation among the students themselves and between students and members of the broader community. Evidence suggests that individuals are changed more by discussions of campaign messages than by directly viewing such messages. ${ }^{16}$

A major challenge of the communications campaign was maximizing its effectiveness with students at the highest risk for type 2 diabetes (due to excess weight) while remaining nonstigmatizing and relevant to the general student population. Consequently, we focused our messages on positive images and activities for youth at this age rather than on the risks or consequences associated with unhealthy behaviors. This is consistent with the broad social psychological literature indicating that positive messages with specific doable behavioral targets are more likely to motivate health behavior changes than messages exploiting fears. ${ }^{17}$

Each study center followed a detailed 'flighting' plan to coordinate the communications campaign with all other study activities and with the school schedule while building on previous messages and setting the stage for the next. Frequent changes in visual materials ensured that messages did not become stale or that posters simply became wall-paper.

\section{Cafeteria line messages}

Experts in nutrition within the study group developed brief messages to be displayed on or near cafeteria serving lines. In total, 10 to 15 pairs of messages were displayed each semester, 1 pair at a time for 1 week each. The pairs were presented in a question-and-answer format. Most messages were related to the nutrition goals, although PE and behavioral topics were occasionally included to promote integration across intervention components.

\section{Physical education messages}

Experts in PE developed brief messages for PE teachers or assistants to announce, while students were engaged in a cool-down period at the end of PE class. Eight PE messages were delivered during each semester, one new message every 5-7 classes. The messages were designed to be 1-3 min long. The topics related to study themes for that semester and to the PE, nutrition and behavioral components of the intervention.

\section{Public address announcements}

Student peer communicators (SPCs) read PA announcements over each school's intercom system or in classrooms during the behavioral intervention component in-class educational activity. ${ }^{4}$ At least eight announcements were read every semester, with each delivered once or 
twice a week. Announcements addressed the semester study themes or current intervention events. SPCs were encouraged to revise the messages using their own words to make the language more relevant and authentic. Study staff and school administrator approval was always secured before delivery. During the last year of the intervention, these PA messages were augmented by audio and video versions of study-specific messages produced and delivered by national celebrities generally recognized and respected by middle school students.

\section{Playback}

In the spring of seventh grade and during the eighth grade year, study staff took photographs of students, alone and in groups, and recorded audio or video clips about the students' personal experiences in the intervention. We asked open-ended questions and used probes, such as 'What makes food healthy?' or 'What's your HEALTHY food?' Selected photographs were placed into centrally designed poster templates along with student quotations and displayed throughout the school. Additional photographs, audio and/or video clips were played to the students as allowed, such as on the PA system, in classroom slide shows or at assemblies. These playbacks lasted up to $20 \mathrm{~min}$.

\section{Student peer communicators}

Student peer communicators were students in the cohort grade who promoted study activities to their peers, assisted with intervention activities on the campus and provided informal feedback to HEALTHY study staff. SPC communications to other students about the project could be characterized as 'buzz marketing,' a promotional strategy that uses opinion leaders to encourage word-of-mouth communications about a program. ${ }^{18}$ This word-of-mouth communication can be more effective than other traditional social marketing strategies because of its perceived credibility and impartiality. ${ }^{19}$ All students within the target grade were eligible to be SPCs, regardless of whether they had enrolled in the study, as long as they were willing and received the approval of classroom teachers. One or two SPCs were selected to represent each class in which the behavioral component of the intervention was administered.

Student peer communicators engaged in study activities up to a maximum of 1 hour per week outside of the classroom. They directly and actively supported study activities as classroom assistants, news reporters, photo-journalists and event specialists who made PA announcements; they also took photographs, independently promoted study aims and modeled student involvement during activities. SPCs were given unique t-shirts with targeted study messages to identify them during the school day and at study-related activities. At the end of each semester, they were invited to participate in a focus group to provide feedback on the intervention. ${ }^{20}$ SPC activities were managed and monitored weekly by the HEALTHY staff members and integrated in all school communication campaigns.

\section{Events}

Events presented the HEALTHY-targeted behaviors in multiple direct and interactive ways. Events were either integrated with other intervention components or intended to provide a connection to overall study goals. The study used the term 'event-in-a-box' (EIB) to describe a formatted package in which key components, materials and detailed instructions were provided to ensure fidelity and make implementation easy and straightforward.

\section{Nutrition intervention EIB: cafeteria learning lab}

During each intervention semester, a cafeteria learning lab activity was conducted during lunch periods. The aims were to teach students about why specific changes were being made to the foods and beverages available and served at the school, to relate how these changes promoted healthier eating habits, and to encourage students to change their own eating habits when 
necessary. Each cafeteria learning lab activity featured one key message, consistent with study nutrition goals and the semester theme. The materials included posters and visuals or props, which were used in a hands-on activity that challenged students to test themselves. For example, in the 'Guess the Sugar' event, students were asked to rank from lowest to highest how much sugar was contained in four popular beverages (water, soda, fruit drink and sports drink). Several students simultaneously used the interactive game display, while the remaining students ranked the same beverages on game cards. Student participants wrote their name and grade on the back of their game cards, which were collected at the end of the lunch period and small prizes (for example, wristbands, disposable digital cameras and key chains) were awarded to the participants. The goal of the event was to inform the students and promote water as a desirable beverage choice, extending the behavioral messaging beyond the classroom in a fun and interactive manner. Another event was a taste test of bottled water versus school tap water. As expected, tap water fared as well as bottled water in blinded evaluation.

\section{Physical education intervention EIB: join the movement}

The 'Join the Movement' EIB emphasized physical activity and promoted awareness that the HEALTHY study was at the vanguard of a national movement. Directions and equipment for five physical activities were provided for setting up in stations through which students rotated. This event promoted, in a fun and interactive way, the physical activity goals and individual behavioral messages that youth were hearing about in other components of the intervention. Activity execution guidelines, a music CD, props to identify activity stations, and elements designed to transform the activity into an interactive game (for example, movement maps, membership cards) were provided in the package. Students participated in five innovative physical activities representing the five states in which HEALTHY sites were located so that youth at a given school would feel ownership of a particular activity, as well as a sense of community with fellow HEALTHY study participants in schools throughout the country. This awareness of being part of a national movement was supported further by the exchange of HEALTHY postcards completed by students and sent to schools from different regions of the country. Overall, the intent of this EIB was to expose youth to new types of physical activities and have them experience these activities as an adventure and special event, rather than just an exercise.

\section{Intervention launch and finale EIB}

In addition to events that targeted specific intervention components, launch and finale events were designed to promote global awareness and enthusiasm for the intervention program overall.

The study launch marked the official kick-off of the intervention at each participating school. This event included a pep rally or similar event for the sixth grade or, if feasible, the entire school. The launch involved pre-event 'teaser' messages to students, a HEALTHY presentation from study and school staff, decorations, an introduction of SPCs and distribution of branded $\mathrm{t}$-shirts. Beyond a general introduction, the event also recognized the students, school administrators, faculty, food service workers and support staff who were helping to make HEALTHY possible at the school. An important aim was to build unity and foster a sense of importance among students as pioneers in a nationwide effort.

The finale marked the intervention's close at the end of the students' eighth grade and was intended to remind students of the intervention goals, encourage them to persist in making targeted changes, recognize and thank participants for their efforts and persistence throughout the program, and provide a sense of closure. 


\section{Student-generated media}

Beginning in the spring semester of seventh grade and continuing throughout the entire eighth grade year, students were actively involved in schoolwide social marketing campaigns.

Although early in the intervention, visual media and intervention events were centrally planned and presented to the students, 'participatory media' formed the core of the communications approach for the latter half of the intervention. With the assistance of study staff, students provided photographs, artwork, audio messages and video clips. The resulting materials more accurately reflected student experiences and sensibilities in a way that a centrally based marketing approach could not. In addition, by having students produce their own communication/marketing products, it was possible to incorporate regional distinctions. Although products from different centers and schools had some overlap, each was tailored to emphasize the local perspective on the study's nationwide scope. Further, recent marketing research suggests that adolescents recognize that they are the targets of marketing campaigns and are more trusting of information that is produced by and shared among peers rather than information that is produced by adults. ${ }^{21}$

\section{Premiums and theme enhancers}

Premiums were broadly distributed to all students in the cohort grade and were not connected to achieving particular HEALTHY targeted behaviors. Premiums were intended to extend the visibility of the study beyond the intervention environment. Premiums were branded with the HEALTHY logo to create a general association with the HEALTHY aims and specifically desired behavior, act as visual cues for that behavior, and establish community among participants. For example, HEALTHY t-shirts with behavioral messaging such as 'let water be your life force' or 'join the movement' were distributed as premiums. School faculty and staff were also given premiums to enhance their involvement in and support for the study as well as to take advantage of their position as role models for students. Theme enhancers were items specifically tied to each semester's theme that helped remind students to adopt target behaviors, for example, a water bottle was distributed during the semester in which drinking more water was emphasized; a pedometer was distributed to prompt students to take an interest in the amount of physical activity they got. The HEALTHY logo itself was designed to encourage queries by others and to provide opportunities for participating students to talk about the intervention, its goals, and their efforts and experiences. In this way, students became spokespersons for the study and internalized principles of HEALTHY themes and activities. Other premiums included folders and a digital yearbook DVD that included celebrity endorsements, substantial video footage and photos of HEALTHY events in their own schools with fellow classmates participating in the study activities. In general, premiums and theme enhancers were intended to motivate, remind, cue, retain and recognize study participants at all levels throughout the course of the trial.

\section{Study personnel and staffing}

Appropriate staffing was necessary to build a strong communications campaign. Just as expertise in the specific intervention modalities targeted was critical (for example, physical activity, nutrition and behavior change), ensuring appropriate staffing to carry out and promote the campaign was essential as well.

\section{Marketing firm/social marketing expertise}

The HEALTHY study partnered with experts in social marketing and brand communications to develop and implement an integrated marketing approach. These experts provided insights gleaned from consumer research to position target behaviors more attractively to study stakeholders (students and their families, school personnel and the study staff). The study's marketing partners also offered guidance in the areas of material development, print production 
and fulfillment, photo and video shoot management, video production, animation and technical support.

\section{Technical/production expertise for student-generated media activities}

With the shift to a 'participatory media' approach, the study designated onsite staff members who could comfortably work with the equipment to take photographs, audio and video recordings of the students and who could use the collected materials to produce professional quality posters and video playbacks. These individuals did not need to be technology experts, but needed to feel comfortable learning to use the technology. They also had to be willing to assume responsibility for operational requirements and management associated with efforts that were focused on students' creative input.

\section{Formative research and feedback}

Social marketing-oriented communications emphasizes consumer and market research to test concepts, message content and design, and to pilot new materials before they are produced and disseminated. ${ }^{22}$ In the HEALTHY study, stakeholders were asked to participate in focus groups and individual interviews during pilot studies that identified preferences and barriers related to visual elements and messages (for example, language, metaphors and images) ${ }^{20}$ This critical feedback was used to develop materials that would be most attractive and compelling to students and acceptable to school administrators and parents.

\section{Discussion}

The HEALTHY social marketing-based communications campaign involved six key characteristics applicable to other health interventions in schools: (1) targeting and responding to multiple audiences, (2) using a broad array of communication modalities, (3) attention to evolving developmental needs of students, (4) awareness of resources required, (5) flexibility and (6) incorporation of local interests.

First, responding to multiple audiences is imperative. The HEALTHY study identity and communications campaigns were developed primarily to build awareness and motivation for core behavior changes among students. However, significant modifications to original creative concepts were sometimes required to ensure that campaign elements were acceptable to the other constituencies of the project, including the sponsor, the study investigators and staff, school districts, school personnel and student families. Accordingly, it is important for social marketers to expect vastly differing perspectives and sensibilities, as well as to understand and accept some degree of resistance resulting from different generational and regional perspectives regarding taste, propriety and undesirable potential influences.

Second, repetition of themes delivered in a variety of modalities and interrelated messaging improves receptivity and reach. ${ }^{23}$ Although classroom-based approaches are often limited to audio and visual communication, the hands-on nature of many of our events was designed to directly and individually involve students in a variety of ways and encourage their creativity. For example, as part of the student-generated media campaign, students could choose to have their picture taken and provide related messaging, or they could create a rap, poem or song to share with the group through a variety of playback venues. Furthermore, message delivery was not limited to static displays or announcements by study and school staff, but included peers and national celebrities as well.

Third, prepare to accommodate evolving adolescent developmental needs. Two challenges we faced were the need to keep campaigns fresh over the 3 years of the intervention and relevant to middle school students as they matured and broadened their interests. Student-generated 
media seemed to address these issues and built on evidence that social norms are a particularly powerful influence on adolescent behavior. ${ }^{24}$ By providing students with messages and images that were created, selected and delivered by their peers, we hoped to influence their beliefs and attitudes and spark excitement and interest about the health behaviors that HEALTHY promoted.

Fourth, consider the resources needed for implementation. We used a number of approaches, each of which required meticulous planning and staff involvement. Some were quite resource intensive and could only be mounted with substantial staffing, most particularly schoolwide events. The scope of a social marketing campaign depends on resource requirements for mounting such efforts.

Fifth, there should be flexibility to permit the appropriate application of new and evolving program components and delivery. Social marketing products are likely to be effective only if they capture the attention of their intended audience, seem authentic and are compelling. As cultural and generational changes can proceed rapidly and sensibilities may vary notably among different subcultures and geographic regions, the particular social marketing elements developed for the HEALTHY study may be of limited utility for others interested in implementing similar school-based programs. Instead, what is likely most transferable is the strategic approach described here. Formative research and involvement of the students and other stakeholders should be a principal consideration in guiding and developing messaging. Furthermore, we did not elect to use the internet as a vehicle for study messaging and events as use of the internet was considered 'screen time' and thus a sedentary activity. Nevertheless, the increasing ubiquity of the internet may very well make this a powerful tool in future efforts of this type. ${ }^{21}$

Finally, adaptation to accommodate local interests and culture and incorporation of participatory media sources enhances program acceptability and success. We believe that the participatory media approach may have been the most potent social marketing tool in this intervention. Although this approach did not replace the need for thorough formative research and material development, it did stretch limited resources and produce communications that were tailored to our target audience. Research suggests that selecting as models individuals who most closely resemble the target in look, dress, language and behavior improves influence and credibility. ${ }^{25}$ In addition, those students who were actively involved may have been more inclined to act consistent with their public statements.

Social marketing-based communications strategies were used to integrate the nutrition, physical activity and behavior intervention components in the HEALTHY study. These strategies were intended to encourage widespread acceptance of changes in the school environment and to motivate students to fully engage in formal intervention activities. Further, we aimed to engage students in all aspects of the intervention with varied learning methods through the use of multiple modalities and repeated exposures to the core study themes and targeted behaviors. We attempted to increase student internalization of study messages through the use of positive, youth-oriented messages and images, and to involve students in delivering these messages both directly and indirectly, as well as formally and informally. The incorporation of student-generated media allowed the messages and visuals to reflect both the developing maturity of the students over the course of middle school and the perspectives specific to the local culture.

\section{Acknowledgements}

Past and present HEALTHY study group members on the Communications Committee were Lynn DeBar (Chair), Tara Blackshear, Jamie Bowen, Sarah Clayton, Tamara Costello, Kimberly Drews, Eileen Ford, Angela Garcia, Katie Giles, Bonnie Gillis, Heather Murphy Grund, Art Hernandez, Ann Jessup, Megan Krause, Barbara Linder, Jeff 
McNamee, Esther Moe, Chris Nichols, Margaret Schneider, Brenda Showell, Sara Solomon, Diane Stadler, Mamie White and Alissa Wheeler. The Communications Committee was supported by the creative teams at the Academy for Educational Development and Planit Agency. We certify that all applicable institutional and governmental regulations concerning the ethical use of human volunteers were followed during this research.

\section{References}

1. The HEALTHY Study Group. HEALTHY study rationale, design and methods: moderating risk of type 2 diabetes in multi-ethnic middle school students. Int J Obes 2009;33(Suppl 4):S4-S20.

2. McMurray RG, Bassin S, Jago R, Bruecker S, Moe EL, Murray T, et al. for the HEALTHY Study Group. Rationale, design and methods of the HEALTHY study physical education intervention component. Int J Obes 2009;33(Suppl 4):S37-S43.

3. Gillis B, Mobley C, Stadler DD, Hartstein J, Virus A, Volpe SL, et al. for the HEALTHY Study Group. Rationale, design and methods of the HEALTHY study nutrition intervention component. Int J Obes 2009;33(Suppl 4):S29-S36.

4. Venditti EM, Elliot DL, Faith MS, Firrell LS, Giles CM, Goldberg L, et al. for the HEALTHY Study Group. Rationale, design and methods of the HEALTHY study behavior intervention component. Int J Obes 2009;33(Suppl 4):S44-S51.

5. Summerbell CD, Waters E, Edmunds LD, Kelly S, Brown T, Campbell KJ. Interventions for preventing obesity in children. Cochrane Database Syst Rev 2005;3:CD001871. [PubMed: 16034868]

6. Grier S, Bryant CA. Social marketing in public health. Annu Rev Public Health 2005;26:319-339. [PubMed: 15760292]

7. Andreasen, A. Marketing Social Change: Changing Behavior to Promote Health, Social Development, and the Environment. Jossey-Bass Inc; San Francisco: 1995.

8. Smith DE, Marcus MD, Lewis CE, Fitzgibbon M, Schreiner P. Prevalence of binge eating disorder, obesity, and depression in a biracial cohort of young adults. Ann Behav Med 1998;20:227-232. [PubMed: 9989331]

9. Aggleton P. Behavior change communication strategies. AIDS Educ Prev 1997;9:111-123. [PubMed: 9167797]

10. Institute of Medicine. Food Marketing to Children and Youth: Threat or Opportunity?. The National Academies Press; Washington, DC: 2006.

11. National Health Service. Choosing health: making healthy choices easier.. National Health Service 2004.. [3 August 2009]. Available at

http://www.dh.gov.uk/en/Publicationsandstatistics/Publications/PublicationsPolicyAndGuidance/ DH_4094550

12. Huhman M, Potter LD, Wong FL, Banspach SW, Duke JC, Heitzler CD. Effects of a mass media campaign to increase physical activity among children: year 1 results of the VERB campaign. Pediatrics 2005;116:e277-e284. [PubMed: 16061581]

13. Wong F, Huhman M, Heitzler C, Asbury L, Bretthauer-Mueller R, McCarthy S, et al. VERB-a social marketing campaign to increase physical activity among youth. Prev Chronic Dis 2004;1:A10. [PubMed: 15670431]

14. Maibach, EW.; Rothschild, M.; Novelli, W. Social Marketing in Health Behavior and Health Education. Mosby; St Louis, MO: 2002.

15. Bauman A. Precepts and principles of mass media campaign evaluation in Australia. Health Promotion J Aust 2000;10:89-92.

16. Noar SM. A 10-year retrospective of research in health mass media campaigns: where do we go from here? J Health Commun 2006;11:21-42. [PubMed: 16546917]

17. Janis IL. Effects of fear arousal on attitude change: recent development in theory and experimental research. Adv Exp Soc Psychol 1967;3:166-224.

18. Rosen, E. The Anatomy of Buzz. Doubleday; New York, NY: 2002.

19. Holdford DA. Using buzz marketing to promote ideas, services, and products. J Am Pharm Assoc 2004;44:387-395. 
20. Schneider M, Hall WJ, Hernandez AE, Hindes K, Montez G, Pham T, et al. for the HEALTHY Study Group. Rationale, design and methods for process evaluation in the HEALTHY study. Int J Obes 2009;33(Suppl 4):S60-S67.

21. Lefebvre RC. The new technology: the consumer as participant rather than target audience. Soc Mark Q 2007;8:31-42.

22. Stead M, Hastings G, McDermott L. The meaning, effectiveness and future of social marketing. Obes Rev 2007;8:189-193. [PubMed: 17316324]

23. McKenna J, Gutierrez K, McCall K. Strategies for an effective youth counter-marketing program: recommendations from commercial marketing experts. J Public Health Manag Pract 2000;6:7-13. [PubMed: 10848486]

24. Abroms LC, Maibach EW. The effectiveness of mass communication to change public behavior. Annu Rev Public Health 2008;29:234.

25. Rogers, EM. Diffusion of Innovations. Vol. 5th edn.. Free Press; New York NY: 2003. 


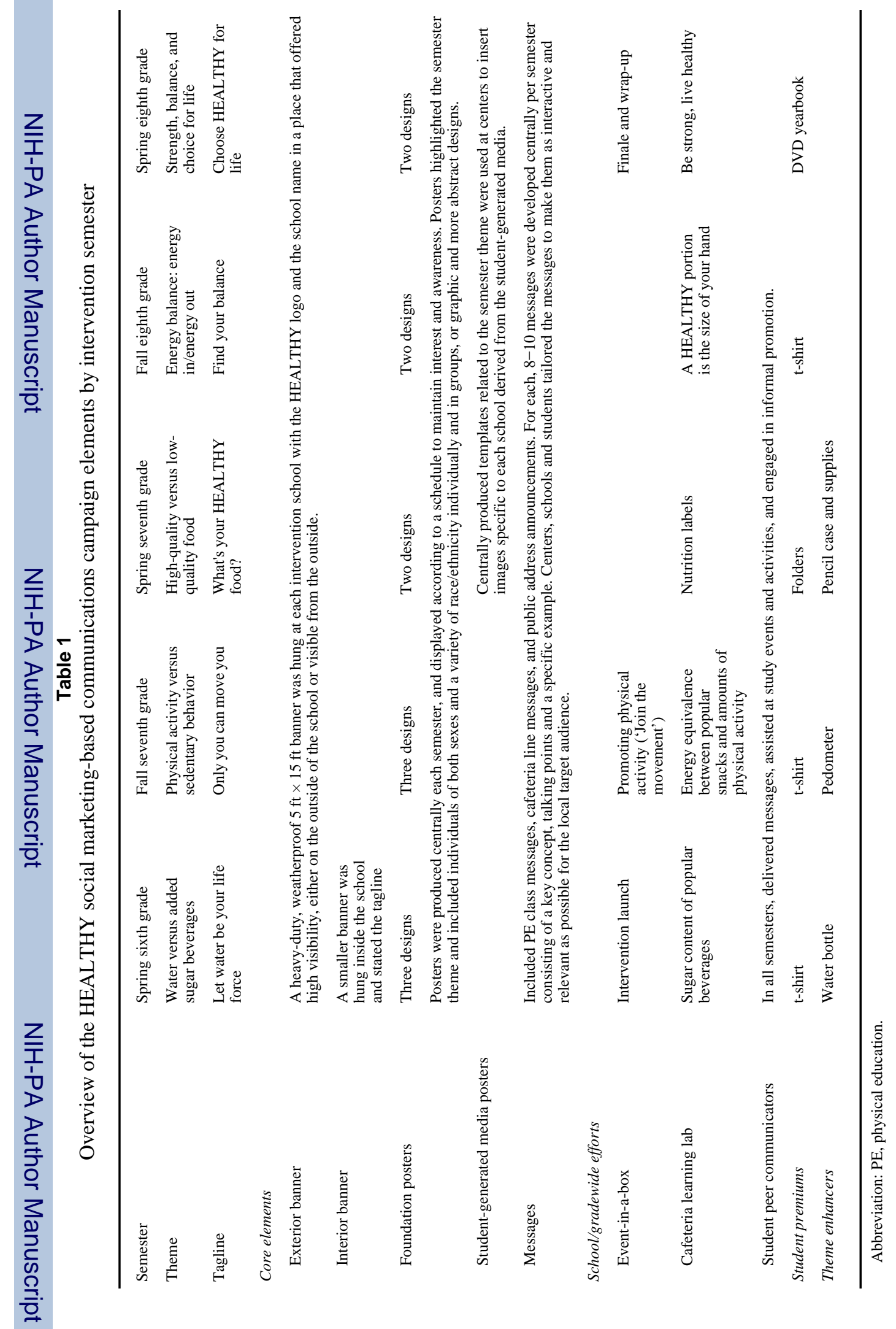

